Check for updates

Cite this: Chem. Commun., 2018, 54, 12986

Received 31st August 2018 Accepted 24th October 2018

DOI: 10.1039/c8cc07092j

rsc.li/chemcomm

\section{Drawing on biology to inspire molecular design: a redox-responsive MRI probe based on Gd(III)-nicotinamide $\uparrow$}

\author{
Michael Harris, ${ }^{a}$ Jacek L. Kolanowski, (D) ${ }^{\mathrm{b}}$ Edward S. O'Neill, ${ }^{\mathrm{b}}$ Céline Henoumont, \\ Sophie Laurent, (D) ${ }^{\text {cd }}$ Tatjana N. Parac-Vogt (D) ${ }^{a}$ and Elizabeth J. New (D)*b
}

\begin{abstract}
A novel, reversible redox-active MRI probe, GdNR1, has been developed for the study of redox changes associated with diseased states. This system exhibits switching in relaxivity upon reduction and oxidation of the appended nicotinimidium. Relaxivity studies and cyclic voltammetry confirmed the impressive reversibility of this system, at a biologicallyrelevant reduction potential. A 2.5 -fold increase in relaxivity was observed upon reduction of the complex, which corresponds to a change in the number of inner-sphere water molecules, as confirmed by luminescence lifetimes of the Eu(III) analogue and NMRD studies. This is the first example of a redox-responsive MRI probe utilising the biologically-inspired nicotinimidium redox switch. In the future this strategy could enable the non-invasive identification of hypoxic tissue and related cardiovascular disease.
\end{abstract}

The non-ionizing, non-invasive and unlimited tissue penetration of magnetic resonance imaging (MRI) offers an exceptional opportunity to visualize biological events with probes that modulate the MRI signal upon a signaling event. ${ }^{1}$ Numerous complexes have been developed for chemical stimuli such as enzymatic activity, ${ }^{2,3} \mathrm{Ca}^{2+}, \mathrm{Cu}^{2+}, \mathrm{Zn}^{2+}, 4,5$ or neurotransmitters, ${ }^{6}$ or characteristics of the chemical environment such as $\mathrm{pH}^{7}$ redox state, ${ }^{8}$ or temperature. ${ }^{9}$ Currently reported approaches to achieving redox-responsive MRI systems include using redox-active metals such as cobalt, ${ }^{10}$ copper, ${ }^{11}$ and manganese,${ }^{12}$ and europium, ${ }^{13}$ selfassembly triggered ligands, ${ }^{14}$ or appended functional groups such as quinols, ${ }^{15}$ thiols ${ }^{16}$ and merocyanine/spyrooxazine. ${ }^{17}$

Local changes in biological redox potential play an important role in signal transduction, influencing many cellular functions. The uncontrolled production of pro-oxidants in oxidative stress ${ }^{18,19}$

\footnotetext{
${ }^{a}$ Department of Chemistry, KU Leuven, Celestijnlaan 200F, Heverlee 3001, Belgium

${ }^{b}$ School of Chemistry, The University of Sydney, NSW 2006, Australia.

E-mail: elizabeth.new@sydney.edu.au

${ }^{c}$ General, Organic and Biomedical Chemistry Unit, NMR and Molecular Imaging Laboratory, University of Mons, Mons 7000, Belgium

${ }^{d}$ Center for Microscopy and Molecular Imaging (CMMI), 8 rue Adrienne Boland, Gosselies 6041, Belgium

$\dagger$ Electronic supplementary information (ESI) available: Characterisation and further NMRD details. See DOI: $10.1039 / \mathrm{c} 8 \mathrm{cc} 07092 \mathrm{j}$
}

is increasingly being understood to play a role in various pathologies, including Alzheimer's disease, cardiovascular disease, obesity, diabetes and arthritis. ${ }^{20-23}$ On the other hand, hypoxia occurs when blood supply to tissues is restricted in a variety of pathologies including solid tumors and atherosclerosis. We are particularly interested in the preparation of reversible contrast agents that can sense dynamic changes in biological redox environments, ${ }^{10,24}$ and here sought to develop a Gd-based reversible redox sensor.

In this study we report Gd-nicotinamide redox sensor 1 (GdNR1), a Gd(III) contrast agent with a redox-sensitive switch that operates at a physiologically-relevant reduction potential (Scheme 1). We chose a nicotinamide-based redox sensor as this moiety is used in the redox-active NAD/NADH cofactor in biological systems.

DO3A derivatives are commonly synthesized starting from DO3A-O ${ }^{t} \mathrm{Bu}$, but due to challenges in purification of the ligand, a less-commonly utilized approach was employed to synthesize GdNR1, enabling a facile final purification step (Scheme S1, ESI $\dagger$ ). After alkylating nicotinamide with 1,3-dibromopropane and isolating the product by precipitation in acetonitrile, this salt was used directly in a one-pot, two-step synthesis with cyclen (2 eq.) followed by addition of excess $t$ Bu bromoacetate. This yielded a mixture of our desired, charged target material and tetra-substituted cyclen (DOTA-O ${ }^{t} \mathrm{Bu}$ ), which could be separated using aqueous/organic liquid-liquid extraction. TFA deprotection of the $t \mathrm{Bu}$ ester groups and a $\mathrm{Cl}^{-}$-exchange column gave the free ligand with a single counter-ion. Lanthanide(III) complexes were then prepared by complexation with lanthanide(III) chlorides in water.

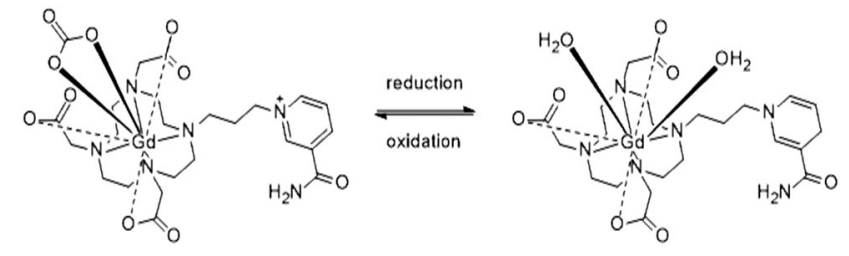

Scheme 1 GdNR1 in oxidized (left) and reduced (right) forms. 
Electrospray ionization mass spectrometry (ESI-MS) of the ligand was performed to confirm the nature of reduced and oxidized species, with studies carried out before deprotection of the tertiary butyl ester groups due to very poor ionization of the reduced-neutral free ligand or complex. The charged nicotinimidium appeared at $677.4(+\mathrm{ve} \mathrm{m} / \mathrm{z})$ and the reduced ligand was found as a sodium adduct (+ve $m / z$ 701.4) (Fig. S9 and S10, ESI $\dagger$ ). This single proton difference confirms the nicotinimidiumto-dihydronicotinamide reduction. ${ }^{1} \mathrm{H}$ and ${ }^{13} \mathrm{C}$ NMR characterization of the analogous diamagnetic La(III) complex showed the loss of the aromatic peaks and appearance of the expected reduced nicotinamide peaks upon reduction of the system (Fig. S11-S14, ESI $\dagger$ ).

Cyclic voltammetry (CV) of the complex revealed well-separated redox peaks consistent with the two electron reduction of the nicotinimidium ring to dihydronicotinamide (Fig. 1). The electrochemical reversibility of the system was confirmed over 12 cycles, highlighting the advantages of our system over previouslyreported contrast agents that exhibit only quasi-reversibility. ${ }^{25}$

To investigate redox-induced changes in the hydration state of the complex, a luminescent Eu(III) analogue was synthesized and the luminescence lifetimes measured in $\mathrm{H}_{2} \mathrm{O}$ and $\mathrm{D}_{2} \mathrm{O}$ with addition of reductant, oxidant and bicarbonate. The hydration number $(q)$ of $\mathrm{Eu}(\mathrm{III})$ complexes can be estimated $( \pm 0.1$ to 0.3 ) using the empirical formula: ${ }^{26}$

$$
q_{\mathrm{Eu}}\left(\mathrm{H}_{2} \mathrm{O}\right)=1.2\left(\Delta k_{\mathrm{obs}}-0.25-1.2 q^{\mathrm{NH}}-0.075 q^{\mathrm{CONH}}\right),
$$

where $q^{\mathrm{NH}}$ and $q^{\mathrm{CONH}}$, the number $\mathrm{OH}$ or CONH groups participating in lanthanide coordination are 0 for this complex, and $\Delta k_{\mathrm{obs}}$ is calculated from the decay rate constants $1 / \tau_{\mathrm{H}_{2} \mathrm{O}}-1 / \tau_{\mathrm{D}_{2} \mathrm{O}}$, expressed in $\mathrm{ms}^{-1}$.

This analysis confirmed a decrease in the water coordination number from 1.9 to 0.3 upon oxidation (in non-degassed MES buffer, pH 7) (Table 1). This corresponds to a change from 2 bound water molecules in the reduced form to 0 . We speculated that binding of a counteranion, promoted by the positively charged oxidized nicotinimidium, was responsible for occluding

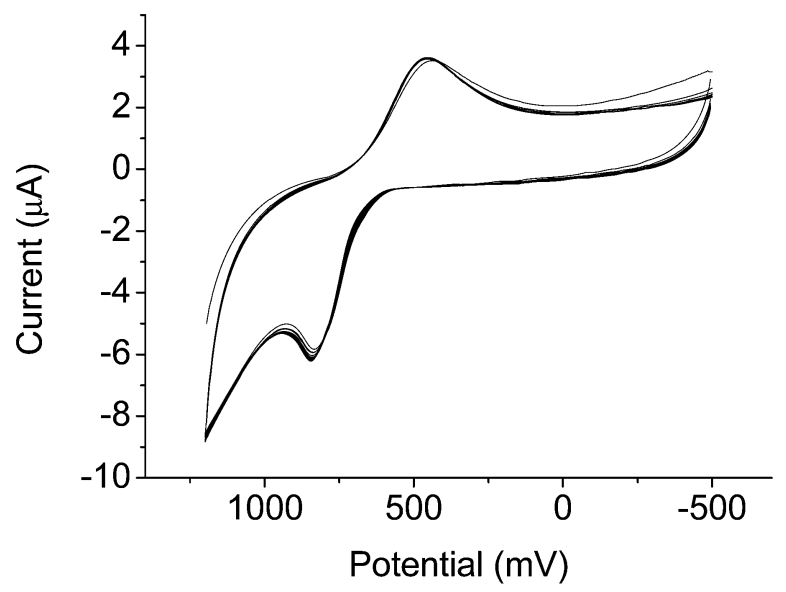

Fig. 1 Cyclic voltammogram of GdNR1 in water containing $0.1 \mathrm{M} \mathrm{KCl}$ as supporting electrolyte for 12 cycles. CV recorded using glassy $\mathrm{C}$ as working electrode, $\mathrm{Ag}^{+} / \mathrm{AgCl}$ as reference electrode, and $\mathrm{Pt}$ wire as counter electrode. Scan rate $100 \mathrm{mV} \mathrm{min}^{-1}$.
Table 1 Luminescence lifetimes and hydration numbers in water or MES buffer (20 mM, pH 7) at $298 \mathrm{~K}$

\begin{tabular}{llll}
\hline & $\tau_{\mathrm{H}_{2} \mathrm{O}}{ }^{a} / \mathrm{ms}$ & $\tau_{\mathrm{D}_{2} \mathrm{O}}{ }^{a} / \mathrm{ms}$ & $q \mathrm{H}_{2} \mathrm{O}$ \\
\hline EuNR1-reduced $^{b}$ (MES, non-degassed) & 0.32 & 0.80 & 1.9 \\
EuNR1-oxidized $^{c}$ (MES, non-degassed) & 0.44 & 0.55 & 0.3 \\
EuNR1-reduced $^{b}+\mathrm{HCO}_{3}{ }^{-}$(10 eq.) & 0.34 & 0.95 & 1.9 \\
(MES, non-degassed) $_{\text {EuNR1-oxidized }}^{c}+\mathrm{HCO}_{3}$ (10 eq.) & 0.42 & 0.56 & 0.4 \\
(MES, non-degassed) $_{\text {EuNR1-oxidized }}^{d}\left(\mathrm{H}_{2} \mathrm{O} \& \mathrm{D}_{2} \mathrm{O}\right.$ degassed) & 0.26 & 0.57 & 2.1
\end{tabular}

${ }^{a}$ Average of 3 measurements that vary by less $0.01 \mathrm{~ms} .{ }^{b}$ Reduced by buffer. ${ }^{c}$ Oxidised by addition of 10 eq. $\mathrm{H}_{2} \mathrm{O}_{2} \cdot{ }^{d}$ Native form in pure water.

water binding. In non-degassed solutions and biological systems alike, bicarbonate is the major coordinating anion, with biological bicarbonate concentrations on the order of $20 \mathrm{mM}$, so we hypothesised that this ion binds to the oxidized form, as has previously been observed for responsive lanthanide complexes. ${ }^{27}$ Addition of $\mathrm{HCO}_{3}{ }^{-}$(10 eq.) to the buffered sample showed no change, and when this sample was oxidized, the $q$ value decreased in the same manner. In comparison, in samples degassed by boiling and purging with argon to remove bicarbonate, the oxidized complex showed $q=2.1$, confirming our hypothesis that bicarbonate binding is responsible for this large change in hydration state. HEPES and MES buffers are reported to be mild reductants which can be used for synthesis of gold nanoparticles from $\mathrm{AuCl}_{4}{ }^{28}$ This, together with a positive reduction peak observed in the CV ( $450 \mathrm{mV}$, Fig. 1) of GdNR1 could result in a partial reduction of the complex upon dissolution in the buffers, and subsequently higher $r_{1}$ and $q$ values observed by the luminescence lifetimes and NMRD measurements in buffered solution.

Nuclear magnetic resonance dispersion (NMRD) was used to study the relaxivity of the system in the oxidized and reduced forms in buffered non-degassed water. The $r_{1}$ values of the native reduced complex in HEPES and MES buffers were 6.9 and $7.5 \mathrm{~s}^{-1} \mathrm{mM}^{-1}$ respectively (Fig. 2 and Table S1, ESI $\dagger$ ). Addition of the reductant sodium dithionite to GdNR1 in buffer showed no significant change to the NMRD profile (Fig. 2). $\mathrm{H}_{2} \mathrm{O}_{2}$ was then used to oxidize the complex in buffered solution and the $r_{1}$ was observed to decrease to $4.6 \mathrm{~s}^{-1} \mathrm{mM}^{-1}$ at $60 \mathrm{MHz}$ and $37{ }^{\circ} \mathrm{C}$ for both buffers.

The NMRD curve at low field confirmed the three-fold change in relaxivity from oxidized to reduced forms (Fig. 2). To further rule out any role for $\mathrm{H}_{2} \mathrm{O}_{2}$ other than as an oxidant, we repeated the experiment with DOTAREM (Gd-DOTA) in clinical preparation, and observed no difference in the presence of excess $\mathrm{H}_{2} \mathrm{O}_{2}$ (Fig. S16, ESI $\dagger$ ).

The system could be reversibly switched between oxidized and reduced forms, although repeated cycling was limited by the buffering capacity due to the acidity of both $\mathrm{H}_{2} \mathrm{O}_{2}$ and sodium dithionite (Fig. 3A). The synthesized version of the probe bearing reduced nicotinamide showed a relaxation rate of $6.9 \mathrm{~s}^{-1} \mathrm{mM}^{-1}$ at $60 \mathrm{MHz}$ and $37{ }^{\circ} \mathrm{C}$. Upon oxidation with $\mathrm{H}_{2} \mathrm{O}_{2}$, the relaxation rate decreased to $3.7 \mathrm{~s}^{-1} \mathrm{mM}^{-1}$. This clear change in relaxation rate with oxidation and reduction could also be observed in phantom images of tubes containing oxidized and reduced GdNR1 (Fig. 3B). 


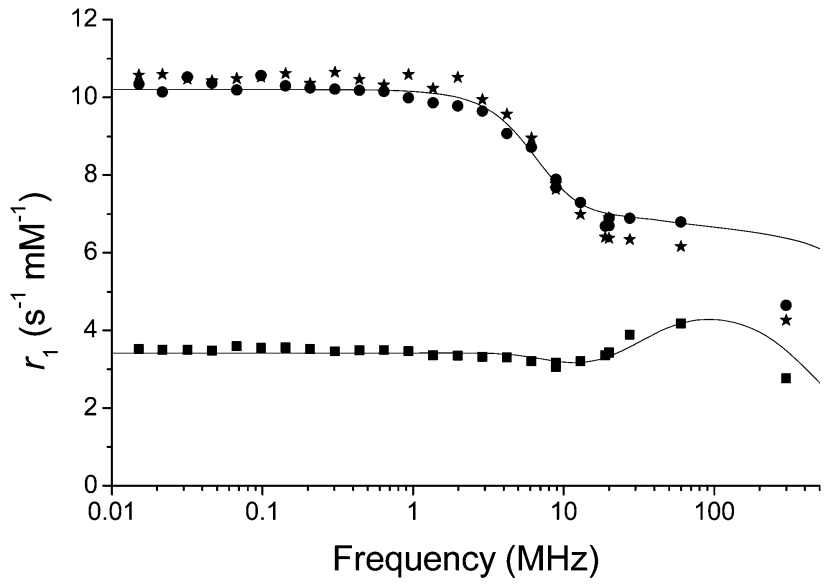

Fig. 2 Proton NMRD profiles of GdNR1 in MES (20 mM, pH 7). Circles: GdNR1 dissolved directly in buffer, non-degassed, squares: addition of $\mathrm{H}_{2} \mathrm{O}_{2}$ (10 eq.) and stars: addition of sodium dithionite (10 eq.). Solid lines represent fitted data.

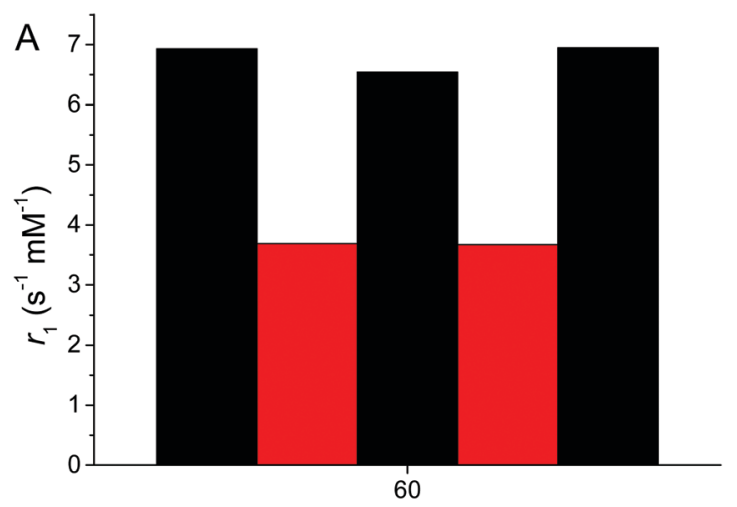

Frequency $(\mathrm{MHz})$

B

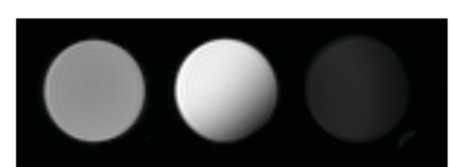

Fig. 3 (A) Relaxivity measured at $60 \mathrm{MHz}$ and $37{ }^{\circ} \mathrm{C}$ with alternating addition of $\mathrm{H}_{2} \mathrm{O}_{2}$ (10 eq. oxidant) or sodium dithionite (10 eq. reductant) (GdNR1 2 mM, MES 100 mM, bicarbonate 2 mM, pH 7). (B) Phantom MRI images of GdNR1 ( $1 \mathrm{mM}$ ) at $300 \mathrm{MHz}$ (left oxidized using $\mathrm{H}_{2} \mathrm{O}_{2}$, middle reduced and right blank) (non-degassed water, HEPES $100 \mathrm{mM}, \mathrm{pH}$ 7.4).

Consistent with our studies of the Eu complex, the $r_{1}$ of the oxidized form was observed to be $7.6 \mathrm{~s}^{-1} \mathrm{mM}^{-1}$ at $60 \mathrm{MHz}$ and $37^{\circ} \mathrm{C}$ when the water was degassed (boiling and argon purging) and the relaxivity did not change significantly upon addition of either oxidant $\left(\mathrm{H}_{2} \mathrm{O}_{2}\right)$ or reductant (sodium dithionite). In contrast, in the presence of bicarbonate, the $r_{1}$ decreased more than double on oxidation (Fig. 4 inset). Upon reduction with sodium dithionite in the presence of bicarbonate, the $r_{1}$ value recovers to near that of the sample in high-purity degassed water of $7.1 \mathrm{~s}^{-1} \mathrm{mM}^{-1}$ at $60 \mathrm{MHz}$ and $37^{\circ} \mathrm{C}$. This is consistent with our hypothesis from the Eu lifetime studies that the changing charge of the complex from +1 to 0 modulates the

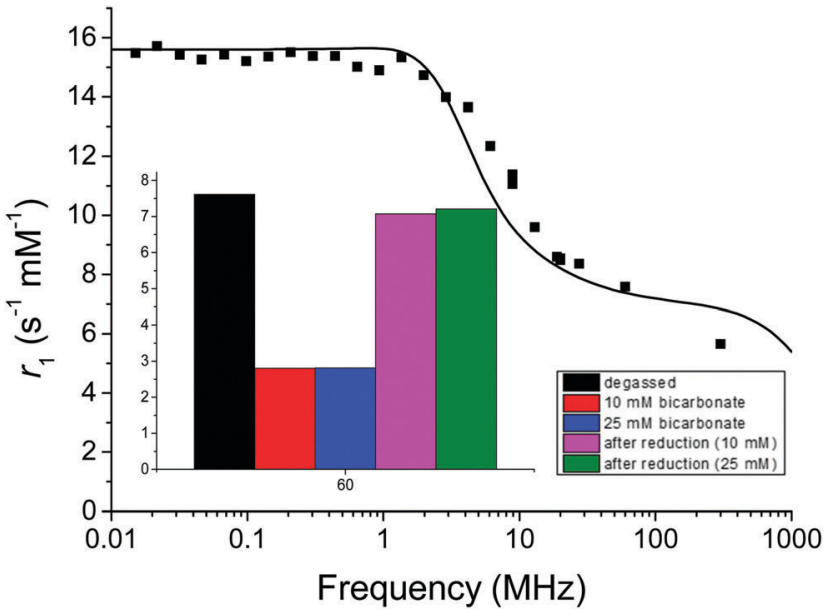

Fig. 4 Proton NMRD profile of GdNR1 in high-purity degassed water at $37^{\circ} \mathrm{C}$. Solid line represents the fitted data. Inset shows relaxivity at $60 \mathrm{MHz}$ for GdNR1 in high-purity degassed water, $10 \mathrm{mM}$ and $25 \mathrm{mM}$ bicarbonate spiked solutions (MES pH 7), and addition of sodium dithionite (10 eq.) to bicarbonate spiked solutions.

binding and release of bicarbonate. This in turn affects water accessibility to the Gd(III) paramagnetic centre, one of the main parameters determining the relaxivity.

Investigating the role of competing species in the relaxation process, we measured the changes in relaxivity upon the addition of citrate, lactate, HSA and in F12 ( $+10 \%$ FBS) cell culture medium (GdNR1 $1 \mathrm{mM})$. Citrate $(0.13 \mathrm{mM})$, lactate $(2.3 \mathrm{mM})$ and cell culture medium did not disturb the relaxivity switching (Fig. S17, ESI $\dagger$ ). In 4\% HSA solution, relaxivity increased indicating non-covalent binding of GdNR1 to the protein associated with an increased rotational correlation time; however, the switching of the system was not impeded (Fig. S17, ESI $\dagger$ ). Lowe et al. previously observed this phenomenon in DO3A derived complexes, where water coordination decreased up to five-fold upon binding of endogenous anions such as bicarbonate and relaxivity dramatically increased with HSA. $^{29}$

In HEPES and MES the oxidized complex showed an increase in relaxivity in the NMRD curve from 20 to $60 \mathrm{MHz}$, characteristic of aggregation. ${ }^{30-35}$ Dynamic light scattering confirmed the presence of $\sim 100 \mathrm{~nm}$ aggregates in the MES buffered solution with $\mathrm{H}_{2} \mathrm{O}_{2}$ added (Fig. S19, ESI $\dagger$ ). However, this aggregation was not visibly observed in the presence of HSA or in cell culture media, so it is likely that under these conditions the complex has sufficient solubility to overcome this problem.

Fitting of proton NMRD profiles to Solomon-BloembergenMorgan theory (ESI $\dagger$ text, Fig. 2 and 4) was performed to evaluate the effect of hydration number and other parameters (especially $\tau_{\mathrm{R}}$ ) on relaxivity, using parameters previously described for Gd(III) complexes (Table S2, ESI $\dagger$ ). ${ }^{22,23}$ As expected for a small DO3A derived complex the rotational correlation time $\left(\tau_{\mathrm{R}}\right)$ is short. Fitting the NMRD data from Fig. 4 before oxidation shows a very similar result to that observed for GdNR1 in high-purity water. Upon oxidation of GdNR1 with $\mathrm{H}_{2} \mathrm{O}_{2}$, the shape of the NMRD profile changed dramatically with a peak in relaxivity occurring at higher Larmor frequency (100 MHz). Such a profile is typical of a 
slow tumbling system, and the slow tumbling implies that aggregation has occurred. However, the relaxivity is much lower than expected for a slow tumbling Gd-complex with inner-sphere water ligand(s), ${ }^{36-39}$ and this low relaxivity implies that the hydration number is decreased and likely $q$ is close to 0 . We then investigated the effects of $\mathrm{pH}$ on relaxivity. $r_{1}$ is constant over $\mathrm{pH}$ $3-6$, decreases by $25 \%$ at $\mathrm{pH} 7$, and further at $\mathrm{pH} 9$ (Fig. S18, ESI $\dagger$ ). This relaxivity decrease between $\mathrm{pH} 6$ and 7 correlates with the first $\mathrm{p} K_{\mathrm{a}}$ of carbonic acid, at $\sim 6.4$, suggesting that it may be result from formation of bicarbonate from water-dissolved $\mathrm{CO}_{2}$ from air and its subsequent coordination to the Gd centre. At $\mathrm{pH} \mathrm{9,} \mathrm{the}$ relaxivity drops to $\sim 4 \mathrm{~s}^{-1} \mathrm{mM}^{-1}$, higher than the relaxivity of $\sim 2.5 \mathrm{~s}^{-1} \mathrm{mM}^{-1}$ (Fig. 4 inset) measured for GdNR1 in pure water spiked with bicarbonate ( $\mathrm{pH} 8-9)$, indicating that the effects of the environment on relaxivity of the complex are a combination of bicarbonate-related as well as other pH-related mechanisms, as described previously for Gd-based complexes. ${ }^{29,40}$

In summary, we report the first example of a reversible redoxresponsive MRI probe based on a Gd(III)-DO3A nicotinamide chelate, and provide a detailed insight into its mechanism and performance. Using a novel synthetic approach, it was possible to produce the final chelate in a few facile steps. The system shows response to sodium dithionite and $\mathrm{H}_{2} \mathrm{O}_{2}$. There is a large signal enhancement upon reduction of the nicotinimidium in the presence of bicarbonate. Luminescence lifetimes of the Eu(III) analogue revealed a change in binding of inner-sphere water molecules upon oxidation and reduction events. Bicarbonate is endogenous to blood serum and would be available to function with this MRI probe for signal suppression of the oxidised form. GdNR1 represents a useful prototype for future contrast agents; for example, by tuning the redox potential, or further conjugation to useful functionalities through the amide of the nicotinamide. In considering future biological application of this probe, we have confirmed its nontoxicity in cultured cells at a concentration of $0.1 \mathrm{mM}$ even after $72 \mathrm{~h}$ incubation (Fig. S20, ESI $\dagger$ ). The potential applications for this complex could include imaging of hypoxic tissue and dynamic monitoring of reducing biological environments.

This work was supported by the Research FoundationFlanders (FWO Flanders, MH), a Westpac Research Fellowship (EJN), Australian Postgraduate Award (ESO), and the Australian Research Council (DP150100649). We acknowledge Dr Nick Proschogo and the Mass Spectrometry Facility at The University of Sydney. High-resolution mass spectrometry at KU Leuven was supported by the Hercules Foundation of the Flemish Government (grant 20100225-7). We thank Professor David Parker for the helpful discussion of results and Mr Marcus Graziotto for assistance with cytotoxicity studies.

\section{Conflicts of interest}

There are no conflicts to declare.

\section{Notes and references}

1 G. Angelovski, Angew. Chem., 2016, 55, 7038-7046.

2 F. Touti, P. Maurin and J. Hasserodt, Angew. Chem., Int. Ed., 2013, 52, 4654-4658.
3 C. Gondrand, F. Touti, E. Godart, Y. Berezhanskyy, E. Jeanneau, P. Maurin and J. Hasserodt, Eur. J. Inorg. Chem., 2015, 1376-1382.

4 E. L. Que and C. J. Chang, Chem. Soc. Rev., 2010, 39, 51-60.

5 C. Shen and E. J. New, Curr. Opin. Chem. Biol., 2013, 17, 158-166.

6 G. Angelovski and E. Tóth, Chem. Soc. Rev., 2017, 46, 324-336.

7 L. Q. Chen and M. D. Pagel, Adv. Radiol., 2015, 2015, 206405.

8 Q. N. Do, J. S. Ratnakar, Z. Kovács and A. D. Sherry, ChemMedChem, 2014, 9, 1116-1129.

9 P. K. Senanayake, N. J. Rogers, K. N. A. Finney, P. Harvey, A. M. Funk, J. I. Wilson, D. O'Hogain, R. Maxwell, D. Parker and A. M. Blamire, Magn. Reson. Med., 2017, 77, 1307-1317.

10 E. S. O'Neill, A. Kaur, D. P. Bishop, D. Shishmarev, P. W. Kuchel, S. M. Grieve, G. A. Figtree, A. K. Renfrew, P. D. Bonnitcha and E. J. New, Inorg. Chem., 2017, 56, 9860-9868.

11 D. Xie, T. L. King, A. Banerjee, V. Kohli and E. L. Que, J. Am. Chem. Soc., 2016, 138, 2937-2940.

12 G. S. Loving, S. Mukherjee and P. Caravan, J. Am. Chem. Soc., 2013, 135, 4620-4623.

13 L. A. Basal and M. J. Allen, Front Chem., 2018, 6, 1-12.

14 D. Ye, P. Pandit, P. Kempen, J. Lin, L. Xiong, R. Sinclair, B. Rutt and J. Rao, Bioconjugate Chem., 2014, 25, 1526-1536.

15 M. Yu, M. B. Ward, A. Franke, S. L. Ambrose, Z. L. Whaley, T. M. Bradford, J. D. Gorden, R. J. Beyers, R. C. Cattley, I. Ivanović-Burmazović, D. D. Schwartz and C. R. Goldsmith, Inorg. Chem., 2017, 56, 2812-2826.

16 B. Jagadish, G. P. Guntle, D. Zhao, V. Gokhale, T. J. Ozumerzifon, A. M. Ahad, E. A. Mash and N. Raghunand, J. Med. Chem., 2012, 55, 10378-10386.

17 C. Tu, R. Nagao and A. Y. Louie, Angew. Chem., Int. Ed. Engl., 2009, 48, 6547-6551.

18 H. Sies, Exp. Physiol., 1997, 82, 291-295.

19 T. C. Jorgenson, W. Zhong and T. D. Oberley, Cancer Res., 2013, 73, 6118-6123.

20 H. K. Vincent and A. G. Taylor, Int. J. Obes., 2006, 30, 400-418.

21 R. Sultana and D. A. Butterfield, J. Alzheimer's Dis., 2010, 19, 341-353.

22 J. W. Baynes, Diabetes, 1991, 40, 405-412.

23 Y.-R. Chen and J. L. Zweier, Circ. Res., 2014, 114, 524-537.

24 E. S. O'Neill, J. L. Kolanowski, G. H. Yin, K. M. Broadhouse, S. M. Grieve, A. K. Renfrew, P. D. Bonnitchab and E. J. New, RSC Adv., 2016, 6, 30021-30027.

25 S. J. Ratnakar, S. Viswanathan, Z. Kovacs, A. K. Jindal, K. N. Green and A. D. Sherry, J. Am. Chem. Soc., 2012, 134, 5798-5800.

26 A. Beeby, I. M. Clarkson, R. S. Dickins, S. Faulkner, D. Parker, L. Royle, A. S. d. Sousa, J. A. G. Williams and M. Woods, J. Chem. Soc., Perkin Trans. 2, 1999, 493-504.

27 M. Giardiello, M. P. Lowe and M. Botta, Chem. Commun., 2007, 4044-4046.

28 S. R. Ahmed, S. Oh, R. Baba, H. Zhou, S. Hwang, J. Lee and E. Y. Park, Nanoscale Res. Lett., 2016, 11.

29 M. P. Lowe, D. Parker, O. Reany, S. Aime, M. Botta, G. Castellano, E. Gianolio and R. Pagliarin, J. Am. Chem. Soc., 2001, 123, 7601-7609.

30 E. Debroye, G. Dehaen, S. V. Eliseeva, S. Laurent, L. V. Elst, R. N. Muller, K. Binnemans and T. N. Parac-Vogt, Dalton Trans., 2012, 41, 10549-10556.

31 E. Debroye, S. V. Eliseeva, S. Laurent, L. V. Elst, S. Petoud, R. N. Muller and T. N. Parac-Vogt, Eur. J. Inorg. Chem., 2013, 2629-2639.

32 M. Harris, S. Carron, L. V. Elst, S. Laurent, R. N. Muller and T. N. ParacVogt, Chem. Commun., 2015, 51, 2984-2986.

33 M. Harris, S. Carron, L. V. Elst and T. N. Parac-Vogt, Eur. J. Inorg. Chem., 2015, 4572-4578.

34 M. Harris, L. V. Elst, S. Laurent and T. N. Parac-Vogt, Dalton Trans., 2016, 45, 4791-4801.

35 M. Harris, H. D. Keersmaecker, L. V. Elst, E. Debroye, Y. Fujita, H. Mizuno and T. N. Parac-Vogt, Chem. Commun., 2016, 52, 13385.

36 E. Debroye, S. V. Eliseeva, S. Laurent, L. V. Elst, R. N. Muller and T. N. Parac-Vogt, Dalton Trans., 2014, 43, 3589-3600.

37 F. Carniato, L. Tei, J. Martinelli and M. Botta, Eur. J. Inorg. Chem., 2018, 2363-2368.

38 Z. Wang, F. Carniato, Y. Xie, Y. Huang, Y. Li, S. He, N. Zang, J. D. Rinehart, M. Botta and N. C. Gianneschi, Small, 2017, 13, 1701830.

39 M. Filippi, D. Remotti, M. Botta, E. Terreno and L. Tei, Chem. Commun., 2015, 51, 17455.

40 J. Hall, R. Häner, S. Aime, M. Botta, S. Faulkner, D. Parker and A. S. d. Sousa, New J. Chem., 1998, 627-631. 